\title{
Silvio Zavala y la historiografía americana. Una vida de vínculos intelectuales
}

Roberto Fernández Castro*

\begin{abstract}
The aim of the author is to propose an assessment of Silvio Zavala's intellectual career, but this time characterized as part of his institutional life, not only through the numerous positions he assumed as founder and director of journals, commissions and research centers, but also as part of circles of intellectuals who, mainly in Mexico, but also in many countries of America, created the first professional "societies of thought" in historical studies. This implies that the approach, instead of being sociological, aspires to apply to the field of history of historiography a hermeneutics of place, action and the articulation of writing, publication, circulation and appropriation of stories.

Key words: Silvio Zavala, Historiography, America, Intellectual history, Hermeneutics.
\end{abstract}

\section{RESUMEN}

El objetivo del artículo consiste en proponer una valoración de la trayectoria intelectual de Silvio Zavala, pero esta vez caracterizada como parte de su vida institucional, no sólo a través de los numerosos cargos que asumió como fundador y director de revistas, comisiones y centros de investigación superior,

* Colegio de Estudios Latinoamericanos, Facultad de Filosofía y Letras, UNAM, correo electrónico: robertofc76@hotmail.com. 
sino también como parte de círculos de intelectuales que, principalmente en México, pero también en numerosos países de América, crearon las primeras "sociedades de pensamiento" profesionales en los estudios históricos. Esto implica que el enfoque, en lugar de ser sociológico, aspira a aplicar al campo de la historia de la historiografía una hermenéutica del lugar, la acción y la articulación de la escritura, publicación, circulación y apropiación de historias.

Palabras clave: Silvio Zavala, historiografia, América, historia intelectual, hermenéutica.

El mundo con que el intelectual se encuentra le parece estar ahi precisamente para ponerlo él en cuestión. José Ortega y Gasset, "El intelectual y el otro"

\section{INTRODUCCIÓN}

$\mathrm{E}$ l estudio de los intelectuales en América Latina ha tenido en el panorama de las revistas culturales de la primera mitad del siglo xx uno de sus ámbitos privilegiados; así ha sido posible seguir los pasos de artistas y escritores que, vinculados a la vanguardia, hicieron de las numerosas publicaciones periódicas los medios de circulación de ideas renovadoras, portavoces de los talentos de su tiempo y portadoras casi míticas de una cultura, por fin, propia y universal a un tiempo. Estas publicaciones, además, tejieron a su alrededor amistades, círculos, sociedades y redes que en muchos casos rebasaron las fronteras nacionales y continentales. ${ }^{1}$

Sin duda, las revistas tienen un papel fundamental en la historia intelectual, pero no son el único medio para consolidar las llamadas "redes intelectuales", y sin demeritar su importancia, me parece que su historia editorial, tanto como el decurso de la vida literaria y académica de quienes las animaron, de quienes les dieron vida o de quienes simplemente colaboraron en ellas, desbordan con mucho sus ámbitos de publicación, difusión y recepción.

Por esta razón, aunque reconozco que en la historia de la historiografía tenemos todavía mucho por hacer al respecto, me parece que no podemos confundir nuestro campo de estudio con los enfoques de la historia intelectual o de la historia cultural. Por un lado, es cierto que las historias de las ideas historiográficas siguen siendo predominantes, pero además, tal parece que nuestras fronteras nacionales o ideológicas nos han impedido valorar de un

$1 \quad$ Véase, por ejemplo el libro coordinado por Alexandra Pita González, Redes intelectuales transnacionales en América Latina durante la entreguerra, México, Universidad de Colima/ Miguel Ángel Porrúa, 2016, 282 pp. 
modo positivo los logros ajenos, ya sea porque la trayectoria institucional de los historiadores todavía no se considera una parte fundamental de su trayectoria intelectual o como un "lugar social, de prácticas científicas y de una escritura".

Michel de Certeau se refiere a la combinación de estas tres condiciones previas cuando habla de la operación historiográfica en La escritura de la historia ${ }^{2}$ condiciones previas, pero actuantes en la escritura histórica. Lo que en un nivel no sólo discursivo, sino también lingüístico, Hans-Georg Gadamer denomina la situación hermenéutica. ${ }^{3}$ Esto quiere decir que el carácter cerrado y estático del "contexto" se abre a una denominación abierta, dúctil, compleja y contradictoria como lo es el horizonte de interpretación. El lugar social entonces soy yo y mundo con los otros e intersubjetivamente constituido; más allá de lo que un determinismo paradigmático o consensuado sugiere bajo el título de las "prácticas científicas".

Mi hipótesis consiste en sugerir que los historiadores, como miembros de "la república de las letras" y como actores políticos que de un modo u otro son, también establecen entre sí medios y espacios de sociabilidad que se traducen no sólo en la publicación de libros y revistas, sino también en la creación de instituciones y empresas culturales, casi siempre relacionadas con la política nacional e internacional, con la administración pública y con la iniciativa privada, a través de amistades, becas, patrocinios o fideicomisos para la realización de viajes o proyectos de investigación personales o colectivos a corto, mediano y largo plazo. ${ }^{4}$ Lo que creo es que si aplicamos una hermenéutica del lugar, la acción y la articulación de la escritura, publicación, circulación y apropiación de historias al estudio de las "sociedades de pensamiento" que también crean entre sí los historiadores, entonces la historia intelectual aplicada al campo de la historia de la historiografía sí puede ser de verdad historia y no sólo sociología.

Por eso se trata de una parte de la historia de la historiografía que nos permite formular un sinnúmero de interrogantes acerca de cómo se vinculan los historiadores, cuyo actuar sólo raramente se da de manera aislada e individual, y casi siempre como un grupo y un conjunto vasto de personas que intersubjetivamente constituyen formas de sociabilidad diversas $y$ heterogéneas, que van más allá de la solidaridad continental o la coincidencia de ideas, creencias y nacionalidades.

2 Michel de Certeau, La escritura de la historia, Jorge López Moctezuma (trad.), México, Universidad Iberoamericana, 1985, pp. 71-129.

3 Hans-Georg Gadamer, Verdad y método, Ana Agud Aparicio y Rafael de Agapito (trad.), Salamanca, Ediciones Sígueme, 1992, 704 pp. (Hermeneia, 7).

4 Además del citado libro de Alexandra Pita, he encontrado también indicaciones metodológicas relevantes en el libro editado por Carlos Altamirano, Historia de los intelectuales en América Latina. II. Los avatares de la “ciudad letrada” en el siglo XX, Buenos Aires, Katz, 2010, 811 pp. 
Considero además que aquí, mejor que en muchos otros casos, es aplicable lo que François-Xavier Guerra denominó "sociedades de pensamiento", una forma de sociabilidad moderna, cuyo principal fin es pensar y, en este caso, asumir la tarea de elaborar una conciencia histórica, pero no porque las instituciones culturales no funcionen, sino porque son aquéllas las que sostienen a éstas, y no por algún defecto hispánico o latino, sino por su origen, yo diría típicamente humano. ${ }^{6}$ La vida de una persona va más allá de sus relaciones intelectuales, por lo que la prosopografía sólo nos entrega un perfil que es necesario completar con otras piezas, que ya no tratan de lealtades, ni de lazos familiares, académicos o políticos, sino de motivaciones personales en las que anidan los vínculos más profundos con nuestra historia, nuestra cultura, nuestros valores y nuestras creencias.

\section{LOS INICIOS EN ESPAÑA}

En tal sentido, el caso de Silvio Zavala posee una relevancia particular. Desde muy joven, cuando abandonó la Facultad de Jurisprudencia de la Universidad Nacional de Sureste, en su natal Yucatán, para continuar sus estudios en la Universidad Nacional, llegó a la Ciudad de México en 1929, poco antes de cumplir los 20 años. Al inicio de sus "primeras jornadas", su talante permitió apreciar la firmeza de sus propósitos y la claridad de su expresión - como ha escrito Andrés Lira, ${ }^{7}$ pero también su capacidad para establecer vínculos con la "clase estudiantil", pues sólo dos años después fue elegido por la Sociedad de Alumnos de la Facultad de Derecho y Ciencias Sociales para ocupar una beca ofrecida por el gobierno de España con el fin de estudiar en la Universidad de Madrid. Esto fue posible, de acuerdo con los oficios entregados por la federaciones de estudiantes, al ser "uno de los más serios de la Universidad Nacional, por la profundidad de sus conocimientos, modestia y

5 François-Xavier Guerra, México. Del Antiguo Régimen a la revolución, 2a. edición, Sergio Fernández Bravo (trad.), Fondo de Cultura Económica, México, 1991. Sobre todo, t. 1, pp. 19-25, t. 2, pp. 331-339.

6 Yo al menos conocí mucho tiempo antes la obra de François-Xavier Guerra que la de Maurice Agulhon, a quien, al parecer desde la década de los setenta se identificó en Francia como "el inventor de la sociabilidad", concepto deudor de la arqueología de Fernand Benoît. En ambos casos pensé que, a pesar de las posibles objeciones, mucho se podría hacer también en el estudio de la historia de la historiografía. Véase Maurice Agulhon, El círculo burgués. La sociabilidad en Francia, 1810-1848, seguido de Una pequeña autobiografía intelectual, Margarita Polo (trad.), edición de Pilar González Bernaldo, Buenos Aires, Siglo Veintiuno, 2009, pp. 9-43 y 165-186.

7 Silvio Zavala, Primeras jornadas, 1931-1937, edición e introducción Andrés Lira, recopilación y notas Alberto Enríquez Perea, México, El Colegio de México, 2009, p. 12. 
compañerismo", además de poder ofrecer a "la clase estudiantil", magníficas observaciones de aquel país, "desde el punto de vista social". 8

Durante este periodo en España inicia Zavala su carrera como historiador profesional. Después de pasar por el Seminario de Historia de las Instituciones de América de Rafael Altamira, ${ }^{9}$ al año siguiente de titularse coronó su doctorado con la publicación de su tesis acerca de Los intereses particulares en la conquista de la Nueva España (estudio histórico-jurídico), aparecida en Madrid en 1933. En el prólogo, Rafael Altamira se encargó de advertir la novedad que encerraba la concepción económica de la historia de la conquista a que respondía la obra. Pero Silvio Zavala publicó por lo menos otros tres estudios históricos extensos en España, los cuales también versaban acerca de instituciones coloniales de América y derecho indiano, además de una contribución breve de historia comparada de la conquista en Las Canarias y en América. ${ }^{10}$

El mismo año de 1933, Silvio Zavala se incorporó como colaborador de la Sección Hispanoamericana del Centro de Estudios Históricos de Madrid, que por entonces tenía sus puntos fuertes en lingüística, historia medieval e historiografía, y donde laboraban Ramón Menéndez Pidal, Américo Castro, Claudio Sánchez Albornoz, Benito Sánchez Alonso, Dámaso Alonso, Ramón Iglesia y el propio Rafael Altamira. Pero ya antes habían pasado también por dicho Centro Eduardo Hinojosa, José Ortega y Gasset, y los mexicanos Alfonso Reyes y Genaro García, quien precisamente se encontraba entonces haciendo gestiones por la parte mexicana, para que Ramón Iglesia llevara a cabo su edición crítica de la Historia de Bernal Díaz del Castillo. ${ }^{11}$

$8 \quad$ Ibid., pp. 15-16.

$9 \quad$ El caso de Rafael Altamira es de especial importancia en esta historia, y aunque resultaría imposible reseñar la trayectoria de todos aquellos historiadores, intelectuales y escritores con los que Zavala estableció una relación fecunda y duradera, cabe decir que no sólo fue el maestro que finalmente lo inclinó por los estudios históricos, sino que además él mismo llevó a cabo una labor de modernización de tal disciplina en España que, haciéndose eco de las preocupaciones literarias y filosóficas de la generación del 98, incluyó como una parte fundamental de su programa el volver a estrechar lazos entre España y las naciones hispanoamericanas. La bibliografía relativa es también aquí abundante y yo mismo he seguido la pista por años, pero cito sólo tres trabajos indicativos: Hebe Carmen Pelosi, "Las redes sociales de Rafael Altamira historiador", Canelobre, núm. 59, 2012, pp. 46-54, Gustavo H. Prado, Las lecciones historiográficas de Rafael Altamira en Argentina (1909). Apuntes sobre ciencia, universidad y pedagogía patriótica, Oviedo, Universidad de Oviedo, 2010, 298 pp. y Palmira Vélez, La historiografía americanista en España 1955-1936, Madrid/ Iberoamericana; Frankfurt an Main/Vervuert, 2007, 453 pp.

10 Biobibliografía de Silvio Zavala, 2a. ed. México, El Colegio Nacional, 1993, págs. 29 y 45.

11 Todas estas relaciones forman parte de lo que Aimer Granados, entre otros investigadores de América Latina, han llamado "relaciones culturales hispano-mexicanas" durante las primeras décadas del siglo xx, es decir, la suma de "los esfuerzos que en el campo de la cultura y la ciencia realizaron tanto mexicanos como españoles con el fin de afianzar una relación que, durante el siglo xIX y, aún para el periodo considerado en este artículo, había estado 
Esta fue una etapa breve, pero fecunda, que terminó cuando Silvio Zavala daba los últimos toques a su importantísimo trabajo de La Utopía de Tomás Moro en la Nueva España, mientras en las calles de Madrid cruzaban no sólo los heridos que combatían a las tropas de Franco en el frente de Guadarrama, sino también las balas. ${ }^{12}$ Zavala, como muchos intelectuales, debió abandonar Madrid en las difíciles circunstancias que sólo dejaban el camino de ValenciaBarcelona-Francia por la frontera de Perpiñán, mientras ante sus ojos se presentaban kilómetros enteros de destrucción y caos. En Francia, sin embargo, apenas se percibía una discreta y por momentos inconsciente preparación para lo inevitable. ${ }^{13}$

\section{La VUelta a MéXico y la AMISTAd con Alfonso ReYes}

Al regresar a México en 1937, Silvio Zavala se incorporó al Museo Nacional en calidad de Secretario durante un año, cuando lo dirigía Luis Castillo Ledón, historiador que había sido gobernador de Nayarit unos seis años antes. Ya entonces tenía clara la necesidad de dignificar la cultura americana, y aunque existían tendencias dispares acerca de los medios para lograrla, la labor que se presentaba como inmediata era "la adopción de métodos, la protección a los centros de investigación y trabajo, la modernización de los elementos bibliográficos", ${ }^{14}$ etcétera. En su opinión, sin estos instrumentos, no sólo no progresaría la ciencia y tampoco habría una liberación de la servidumbre con respecto al pensamiento ajeno. Zavala se pronunció entonces por "democratizar la ciencia", exclaustrándola y reclutando para ella también a quienes se encontraran distantes por la pobreza o la geografía, y para tal fin, la acción pública y privada debían sostener mediante un plan orgánico, una profunda revolución para abrirnos al mundo y dar aliento a nuestra cultura.

En este mismo año Silvio Zavala hizo el primer intento de fundar en México algún centro de preparación de historiadores jóvenes, tal como lo había visto funcionar en Madrid. Gracias a la ayuda de un estimado compañero

pasando por distintos momentos y conflictos de carácter hispanofóbico, aunque también hispanofílico. Pero evidentemente en esta definición también se deben los esfuerzos que uno y otro país realizaron con el fin de universalizar la cultura, la educación y la ciencia producida en cada una de estas naciones". Aimer Granados, "La corriente cultural de la JAE en México: El Instituto Hispano-Mexicano de Intercambio Universitario, 1925-1930", Revista de Indias, España, vol. LXVII, núm. 239, enero-abril de 2007, pp. 103-124.

12 Jean Meyer (coord.), Egohistorias: El amor a Clio, México, Centre d'Etudes Mexicaines et Centramèricaines, 1993, p. 216.

13 Al respecto puede verse, por ejemplo, el libro de James D. Wilkinson, La resistencia intelectual en Europa, traducción de Juan José Utrilla, México, Fondo de Cultura Económica, 1989, pp. 37-118 y $277-295$.

14 Silvio Zavala, Primeras jornadas, p. 129. 
de estudios, la realización del proyecto tuvo lugar en la Universidad Nacional Autónoma de México (UNAM), donde se concedieron becas a un reducido grupo de alumnos, procurando adiestrarlos en la paleografía y el trabajo de investigación de la época de la colonización española, y teniendo por sede el mismo Museo Nacional de la calle de Moneda núm. 13. Sin embargo, este proyecto fracasó muy pronto, tanto por la imposibilidad de los alumnos de dedicar tiempo completo, como por los viajes que llevaron a Silvio Zavala a los Estados Unidos y América del Sur, pues en 1938 obtuvo una beca de la Fundación John Simon Guggenheim por dos años.

De su regreso a México en 1937 data la publicación de La Utopía de Tomás Moro en la Nueva España, bajo el sello editorial de la Antigua Librería Robredo de José Porrúa e hijos, y con una introducción de don Genaro Estrada. En ella Zavala se ocupó de la explicación del ideario de Vasco de Quiroga y de su inspiración en el orden social propuesto por Tomás Moro en La Utopía, no sólo para llevar a cabo sus grandes esfuerzos en defensa de los indios, sino también para fundar sus hospitales-pueblos. No nos podemos ocupar ahora de la importancia del libro en su contenido, pero sí conviene recordar que formó parte de la Biblioteca Histórica Mexicana de Obras Inéditas que, emulando añejas colecciones decimonónicas, se publicó también en dos series, la primera a cargo de Genaro Estrada, y la segunda, tras su fallecimiento, a cargo de Silvio Zavala, quien contrario a la variedad de obras espigadas por su antecesor, optó por concentrarse en la publicación, entre 1939 y 1943, de los 16 volúmenes del Epistolario de Nueva España recopilados por Francisco del Paso y Troncoso.

Otro aspecto que nos interesa en este caso es que poco antes de su fallecimiento, acaecido el 29 de septiembre de 1937, Genaro Estrada invitó a Silvio Zavala para colaborar en un número de la ya célebre revista Sur, fundada en 1934 por Victoria Ocampo, el cual debía formarse con trabajos de autores mexicanos reunidos a través de otro de sus fundadores, Alfonso Reyes, en ese momento también embajador de México en Argentina, y quien recibió la colaboración de Zavala, "Indigenistas del siglo XVI", un breve artículo que en efecto se publicó en Buenos Aires en el número 42 de marzo de 1938. Tan sólo dos números antes Alfonso Reyes había publicado también en Sur su artículo de "Utopías americanas", fruto de su propio estudio de la Utopía de Moro. ${ }^{15}$ Tal vez el tema en común fue lo primero que acercó a

15 Como se verá, Alfonso Reyes fue una figura clave en la historia intelectual de Silvio Zavala. Para dar noticia acerca de toda su vida y su labor literaria, también han sido necesarias innumerables páginas, remito ahora sólo a algunas que complementan el ámbito geográfico americano en el que habría de coincidir con la labor de Zavala: América en el pensamiento de Alfonso Reyes, prólogo y selección de José Luis Martínez, México, Fondo de Cultura Económica, 2012, 201 pp. 20 epistolarios rioplatenses de Alfonso Reyes, Serge I. Zaïtzeff (comp.), México, El Colegio Nacional, 2008, 425 pp. Alfonso Reyes y los estudios latinoamericanos, edición de Adela Pineda Franco e Ignacio M. Sánchez Prado, Pittsburgh, Universidad de Pittsburgh. Instituto Internacional de Literatura Iberoamericana, 2004, 360 
Reyes y Zavala, pero tuvo como mediador a uno de los más grandes diplomáticos y bibliógrafos de México, y como escenario una de las revistas fundamentales de la historia intelectual americana. Esto llamó por primera vez la atención de los historiadores sudamericanos hacia el trabajo de Silvio Zavala. ${ }^{16}$

De vuelta a México después de terminar sus labores diplomáticas en la América del Sur, Alfonso Reyes tuvo la oportunidad de visitar a Zavala, siendo éste todavía Secretario del Museo Nacional, pero no sin antes recomendarlo en la capital argentina con Ricardo Levene, dos veces decano de la Facultad de La Plata, Presidente de la Junta de Historia y Numismática, y Presidente de la Academia Nacional de Historia, entre otras distinciones. A él se le había encargado una obra colectiva sobre historia de América, contando para cada país con un especialista, y Alfonso Reyes sugirió a Zavala para México.

\section{La Revista de Historia de América}

En 1938, el doctor Pedro C. Sánchez, director del Instituto Panamericano de Geografía e Historia (IPGH), había depositado en Zavala su confianza para el proyecto de la Revista de Historia de América del Instituto, cuyo primer número apareció en marzo, teniendo por director fundador a Silvio Zavala y a Francisco Monterde y Felipe Texidor como editores. Uno escritor y académico de la Lengua y el otro bibliógrafo y editor de origen barcelonés.

Entre los propósitos de la revista que se expusieron en ese primer número destacaba la ventaja que ofrecería el conocimiento de los problemas del continente para escribir con mayor acierto las historias nacionales. Después, se ponía énfasis en los vínculos culturales, institucionales, de idioma y de tradición que durante la colonización, el período de la independencia y la separación política de las naciones de América había privado entre ellas,

pp. Fred P. Ellison, Alfonso Reyes y el Brasil. Un mexicano entre los cariocas, México, Consejo Nacional para la Cultura y las Artes, 2000, 267 pp. Alfonso Reyes, Vocación de América. Antología, prólogo y selección de Víctor Díaz Arciniega, México, Fondo de Cultura Económica, 1989, 398 pp. Alfonso Reyes y los intelectuales colombianos. Diálogo epistolar, recopilación, introducción y aclaraciones Adolfo Caicedo Palacios, Bogotá, Universidad de Los Andes, 2009, 409 pp.

16 Domingo Amunátegui Solar, ilustre historiador chileno que más tarde llegaría a ser rector de la Universidad de Chile y ministro de Instrucción Pública, fue uno de los primeros que se interesó en dicho trabajo, también por sugerencia de Reyes. Para todo esto puede verse el libro Fronteras conquistadas. Correspondencia Alfonso Reyes/Silvio Zavala, 1937-1958, compilación, introducción y notas de Alberto Enríquez Perea, México, El Colegio de México, 1998, pp. 33-37. Para situar el artículo de Zavala en el contexto, no de la revista Sur, porque esto merecería un espacio aparte, sino de las relaciones de los intelectuales mexicanos con la revista, véase México en Sur, antología, edición e introducción de Gerardo Villadelángel Viñas, México, Fondo de Cultura Económica, 2014, 925 pp. (Tezontle). 
mientras que en el caso del Brasil y los Estados Unidos, existían atractivos temas de historia de límites, relaciones comerciales e influencias del espíritu. En la revista no se dejarían de rescatar las aportaciones regionales como de interés continental para su valoración universal como auténtica y honda expresión de los pueblos americanos. Asimismo, tomando en cuenta la transformación del instinto de simpatía de los investigadores de América, en una conciencia científica acentuada en los últimos años, la publicación deseaba contribuir al acercamiento de los investigadores, ofreciendo periódicamente estudios, documentos, informaciones científicas y reseñas bibliográficas sobre la historia del continente. Y la honradez de estos propósitos, se decía, quedaba comprobada por la finalidad puramente científica del Instituto que patrocinaba moral y económicamente la obra.

Aunque para 1939 y 1940, en cartas enviadas a Alfonso Reyes, Zavala reconoció algunos defectos en la revista y lamentó no poder darle todo el impulso que necesitaba, el primer número contó, nada menos que con la colaboración de su maestro Rafael Altamira, de Lewis Hanke (animador de la empresa a quien Zavala también conocía desde su estancia en España), los citados Ricardo Levene y Alfonso Reyes, el exiliado español José Moreno Villa, un artículo del mismo Zavala, y la ayuda, desde entonces, del historiador hondureño, ya bien conocido en México, Rafael Heliodoro Valle, quien tomó a su cargo la elaboración de la bibliografía de historia de América ofrecida en la revista. ${ }^{17}$

Por lo demás, los viajes de Zavala no fueron del todo negativos para la revista, en primer lugar porque para el segundo año recibió ayuda de diversos países, y después, porque así pudo darse cuenta de que las bases de la investigación moderna hispanoamericana descansaban sobre todo en Argentina y Estados Unidos, lo que hacía todavía más necesario animar otros ambientes. Esto fue lo que relató Zavala a Alfonso Reyes en una carta de abril de 1939, en cuya respuesta Reyes, además de expresar su completo acuerdo, coincidió con el historiador en su deseo de reforzar las investigaciones hispanoamericanas en México, con el fin de ponerlas a la altura de otros países del continente.

\section{La Casa de España y El Colegio de México}

Hacia abril de 1939 Alfonso Reyes ya había sido nombrado presidente del Patronato de La Casa de España en México, de modo que cuando también

17 Para valorar la inmensa contribución de Rafael Heliodoro Valle en favor de la cultura americana en esos años, véase por ejemplo Edición anotada de las entrevistas de Rafael Heliodoro Valle en la revista Universidad. Mensual de Cultura Popular 1936-1938, coordinación general, edición y estudio preliminar, Raquel Mosqueda Rivera, equipo editorial, María de Lourdes Ángeles Trujillo, Víctor Alejandro Bravo Morales, Dafne Iliana Guerra Alvarado, Lucero Alejandra Rivera Cano, México, Instituto de Investigaciones Filológicas, UNAM, 2015, CCXI-413 pp. 
Zavala estuvo de vuelta en la Ciudad de México, a finales de 1940, se encontró con que el exilio español en México se prolongaría indefinidamente, y muchas cosas se preparaban ya para aprovecharlo. ${ }^{18}$ Una de ellas fue la idea propuesta por Zavala a Reyes de crear una Biblioteca Latina Hispanoamericana, pues con el buen número de latinistas que se encontraban dispersos con la guerra y la necesidad que había de poner al servicio de los estudiosos todo el caudal de cultura de los siglos XVI y XVIII que se encontraba escrito en latín, bien podría intentarse la labor de traducción y edición de obras como las de Pedro Mártir, Juan López de Palacios Rubios, Fray Bartolomé de Las Casas, Joseph de Acosta, Juan de Solórzano y Juan José de Eguiara y Eguren, entre otros. ${ }^{19}$

La Casa de España en México, que en agosto de 1938 había abierto sus puertas para recibir a los intelectuales de la península, gracias al apoyo del gobierno del presidente Lázaro Cárdenas, después de dos años se transformó en El Colegio de México, teniendo a Alfonso Reyes como presidente y a Daniel Cosío Villegas como Secretario. Ambos invitaron a Zavala a colaborar en El Colegio con el único compromiso de continuar su propio trabajo de investigación de tiempo completo. El antiguo proyecto de un centro de estudios históricos como el de Madrid, tuvo entonces una nueva oportunidad. ${ }^{20}$

Silvio Zavala se reunió con el filósofo José Gaos y el sociólogo José Medina Echavarría para formular un anteproyecto de apertura de centros de preparación de estudiantes, con becas de tiempo completo y que aceptaran dedicarse por entero a las ramas que ahí se cultivarían: historia, literatura, ciencias sociales y filosofía. Habituados a esa forma de trabajo en su patria de origen, los maestros españoles convinieron en la utilidad del enfoque y les pareció que de dicha manera, aunque su presencia en México se interrumpiera cuando las circunstancias de la vida política de España y de Europa en general

Digo aprovecharlo porque coincido con quienes han señalado el hecho de que los intelectuales republicanos españoles no fueron quienes "todo trajeron" a México, pues de haber existido las condiciones necesarias, ni siquiera se les habría invitado. Cabe recordar una vez más investigaciones como la de Xavier-Guerra en el sentido de la continuidad entre el "Antiguo Régimen" y la Revolución, el impulso dado a la moderna cultura liberal mexicana durante el Porfiriato, o la profunda transformación educativa del país en los años posteriores a la lucha armada.

19 La mayoría de estos historiadores y tratadistas fue en efecto traducido y editado en México en los años posteriores con la ayuda de maestros del exilio español como Agustín Millares Carlo, con mexicanos como él, que escribió un largo estudio para la obra de Palacios Rubios, y también con el respaldo de las casas editoras de Robredo, Porrúa, La Casa de España y el recién nacido Fondo de Cultura Económica, que dirigía Daniel Cosío Villegas desde su fundación en 1937.

20 Véase Clara E. Lida, La casa de España en México, con la colaboración de José Antonio Matesanz, México, El Colegio de México, 1988, 201 pp. (Jornadas, 113). Clara E. Lida y José Antonio Matesanz, El Colegio de México: una hazaña cultural 1940-1962, México, El Colegio de México, 1990, 395 pp. (Jornadas, 117). 
cambiaran favorablemente, dejarían discípulos mexicanos que vendrían a comprobar que su paso había dejado simientes duraderas al país receptor, y con ello satisfarían plenamente la deuda de gratitud que sentían ante la actitud inteligente y generosa de México, de recibirlos y permitirles la continuación de sus propios trabajos. ${ }^{21}$

Al principio Reyes se opuso a convertir El Colegio en una "escuelita", pero la selección de los estudiantes mexicanos e hispanoamericanos que dio a El Colegio una dimensión continental, así como la atracción de Cosío Villegas por el magisterio, tanto como su talento de administrador, dieron forma al proyecto que el 14 de abril de 1941 vio nacer el Centro de Estudios Históricos (CEH) ${ }^{22}$ abriendo camino para los Centros de Lengua y literatura y de Ciencias Sociales, además del fecundo Seminario de Historia del Pensamiento en Lengua Española que dirigió José Gaos.

Los cursos del Centro comenzaron otra vez en el Museo de la calle de Moneda 13, pero esta vez en las instalaciones de la Escuela Nacional de Antropología e Historia (ENAH) y compartiendo con sus estudiantes una valiosa biblioteca de arqueología, etnología e historia. Ésta se encargaría, en los años cuarenta, de otorgar el grado de maestría a los alumnos del Centro que presentaran y defendieran una investigación de cierta envergadura, según convenio firmado por el presidente del Colegio (Alfonso Reyes), el rector de la UnAm (Alfonso Caso), el director del CEH (Silvio Zavala) y el director de la ENAH (Daniel Rubín de la Borbolla).

En cuanto al historiador que se quería formar, se insistió en el apego a la búsqueda libre de la verdad mediante el conocimiento directo de las fuentes del pasado, con el único límite de estudiar la historia hispanoamericana y especialmente la de México, ya que eran las únicas historias de las que se tenía seguridad de poseer a la mano los medios para hacerlas, medios que además eran potencialmente ricos. Añadiéndose a esto la obligación que se sentía de hacer contribuciones originales a la historia propia. A este respecto, Clara E. Lida ha señalado que al proclamar su propósito de cultivar la historia hispanoamericana con énfasis especial en la de México, el Centro recogió

21 Silvio Zavala, "Orígenes del Centro de Estudios Históricos de El Colegio de México" en Cincuenta años de historia en México, coord. Alicia Hernández Chávez y José Miño Grijalva, México, El Colegio de México, 2 v., v.1, pp. 23-25. Puede verse además el Anexo 1 "Instituto de Historia", documento del 13 de diciembre de 1940 redactado por Zavala, en Fronteras conquistadas. Correspondencia Alfonso Reyes/Silvio Zavala 1937-1958, compilación, introducción y notas de Alberto Enríquez Perea, México, El Colegio de México, 1998, (Colección testimonios, 3), pp. 307-310.

22 En un documento fechado el 13 de diciembre de 1940, y depositado ahora en el Archivo Incorporado "Silvio Zavala", del Centro de Documentación de la Biblioteca Nacional del Instituto Nacional de Antropología e Historia, el centro aparece bajo la denominación de "Instituto de Historia". Véase, Fronteras conquistadas, pp. 307-310. 
la inquietud nacionalista predominante en el país en esos momentos, que en múltiples ocasiones tomó la forma de "una arrobada curiosidad por sí mismo". ${ }^{23}$

La metodología para este historiador también fue muy clara. Se procuraría más alentar un trabajo riguroso, certero y sólido científicamente que estimular las genialidades espontáneas. La investigación, la elaboración de materiales nuevos, la interpretación exacta y cuidadosa de las fuentes eran las metas. Ni repeticiones, ni plagios, ni ficciones; había que producir frutos tangibles. Las razones para adoptar tales posturas fueron el interés por conocer las riquísimas fuentes que en Hispanoamérica permanecían inexploradas a pesar de las posibilidades que ofrecían, rescatándolas así del olvido y del peligro de la destrucción; al mismo tiempo que se podrían superar las tradicionales polémicas que sustituían la información factual con la diatriba partidista. ${ }^{24}$

Lo curioso en la formación de los estudiantes del Centro es que no fue sino hasta la generación de 1946-1949 cuando el aprendizaje del idioma alemán se vio sustituido por el francés y el inglés, quizá, como lo advierte Clara E. Lida, como reflejo de la victoria aliada en la Guerra Mundial. Pero tampoco debemos olvidar que la formación que los exiliados traían consigo era fundamentalmente de procedencia germana, y por otro lado, que en toda América comenzaba a gestarse la vida de la posguerra con todo lo que política y económicamente implicaría.

Por lo que toca al núcleo básico de profesores del Centro, éste lo formaron quienes se dedicaron a él casi por entero: Silvio Zavala, Rafael Altamira, Ramón Iglesia, Concepción Muedra, Agustín Millares Carlo, José Miranda y José Gaos. Según Clara E. Lida, a quien hemos venido siguiendo para la historia del CEH, Zavala, Millares y Muedra formaron el grupo considerado "neo-positivista" entre los profesores del Colegio, a los que se agregaría Rafael Altamira con todo su prestigio y sus 78 años al llegar a México en 1944. Pero entre "lo mejor de lo mejor", según palabras de Cosío Villegas, en el CEH también estuvieron Paul Kirchhoff, Manuel Toussiant, Arturo Arnaiz y Freg, Pablo Martínez del Río, Jorge A. Vivó, Juan B. Iguíniz, José I. Dávila Garibi, Amancio Bolaño e Isla, Wigberto Jiménez Moreno, Francisco Barnés, José María Miquel i Vergés, Josep Carner, Rafael Sánchez Ventura, Javier

23 Clara E. Lida y José Antonio Matesanz, El Colegio de México, p. 114.

24 En este sentido, el primer trabajo con el que Silvio Zavala contribuyó en la labor editorial de El Colegio fueron los ocho tomos de las Fuentes para la historia del trabajo en la Nueva España, editados en colaboración con María Castelo, pero también preparó un trabajo destinado a los no especialistas, los Ensayos sobre la colonización española en América, que publicados primero en 1943 con el pie de imprenta de la Universidad de Pennsylvania, en su edición española del año siguiente por la editorial Emecé de Buenos Aires, ganó el puesto de libro del mes, sección originales en español. Acerca de la importancia de este libro puede verse mi artículo "Liberalismo y civilización en la historia de la colonización española", en Escribir la historia en el siglo XX. Treinta lecturas, Evelia Trejo y Álvaro Matute, (eds.), México, Instituto de Investigaciones Históricas, UNAM, 2009, p. 127-144. 
Malagón, entre otros, llegando incluso a participar Alfonso Reyes y Daniel Cosío Villegas.

La dirección de Silvio Zavala en el CEH mantuvo un ambiente de vigilancia y trabajo constantes a través de frecuentes informes de los profesores sobre los becarios y de éstos sobre sus investigaciones, además de las reuniones que Zavala sostenía con los profesores para cambiar impresiones del curso que finalizaba y del que iniciaría. Otra práctica que Zavala hizo cundir entre los demás Centros de El Colegio fue estimular a los estudiantes para que publicaran en revistas especializadas y se iniciaran como profesionales, tradición que sólo recuperó el $\mathrm{CEH}$ de manera transitoria cuando Zavala, después de una larga ausencia, regresó en 1963 para asumir la presidencia de El Colegio y volvió a figurar como profesor del Centro.

\section{LA INTERNACIONALIZACIÓN DE LOS ESTUDIOS HISTÓRICOS}

Hasta 1956, año en que Silvio Zavala dejó de ser director del CEH para cumplir con su cargo de consejero cultural de la embajada de México en Francia y de delegado permanente de México ante la Organización de las Naciones Unidas prara la Educación, la Ciencia y la Cultura (UNESCO), en París, la historia del CEH llegó a su primer ciclo. Gracias a la ayuda económica de la Fundación Rockefeller de 1943 a 1948 para becas, libros, investigación, sueldos, viajes, etcétera, el Centro no sufrió embates económicos, pero en 1949, al cesar aquella, hubo una contracción en el presupuesto, los alumnos más destacados de las primeras tres promociones consiguieron ir becados a Francia y los Estados Unidos, pero la Universidad Nacional absorbió de tiempo completo a muchos de los miembros de El Colegio al consolidar la profesionalización de las carreras humanísticas. Fue así como los años cincuenta no depararon al Centro la preparación de nuevos historiadores, sino la continuación de investigaciones históricas bajo la dirección de Cosío Villegas, aunque todavía nominalmente con la de Silvio Zavala.

En realidad, Zavala se alejó del CEH desde 1947 al aceptar la Dirección del Museo Nacional de Historia de Chapultepec (1946-1954), y presidir la Comisión de Historia del IPGH (1947-1965). Sin contar además sus numerosas estancias como profesor visitante en universidades de América y Europa. Aun así, todavía el 6 de enero de 1947, los miembros de El Colegio de México pudieron celebrar con Silvio Zavala su ingreso como miembro titular vitalicio en El Colegio Nacional. Zavala fue conducido hasta ahí, de nuevo gracias a la recomendación de Alfonso Reyes, quien con Antonio Caso, Mariano Azuela, Diego Rivera, José Vasconcelos e Ignacio Chávez, entre otros, figuró entre los miembros fundadores de aquella institución que, inspirada en El Colegio de Francia, Manuel Ávila Camacho creó ante la "necesidad del Estado" de 
incentivar el desarrollo de la cultura científica, filosófica y literaria en sus líneas de investigación y difusión, con el objeto de "afirmar la cultura del pueblo mexicano" bajo la fórmula de "Libertad por el saber" que, lamentablemente, sólo sería posible mediante el triunfo de aquello que Alfonso Reyes llamaba la alta cultura.

Los últimos meses de 1947 son todavía más importantes para la vida intelectual del país. La creación oficial de la Comisión de Historia del IPGH fue un acontecimiento principal para la historiografía mexicana. En la IV Asamblea del Instituto celebrada en Caracas, el gobierno de México se comprometió a instalar la Comisión a través del Instituto Nacional de Antropología e Historia (INAH), que dirigía entonces el arquitecto Ignacio Marquina, y de proceder a la inmediata iniciación de sus actividades. El gobierno de México pretendió y consiguió con esto estrechar la colaboración entre el INAH y el IPGH en los campos de todas las ciencias afines a la historia. Primero nombró a Zavala, quien ya era director del Museo Nacional de Historia, como su miembro nacional ante la Comisión de Historia, después, el comité ejecutivo del IPGH, sabedor de que la sede de la Comisión sería México, eligió a Zavala presidente interino de la misma, y éste a su vez, en uso de sus facultades, eligió como su secretario interino al antropólogo Daniel Rubín de la Borbolla, director del Museo Nacional de Antropología. Así, el gobierno de México intervino en la instalación de la Comisión de Historia tanto o más que como lo había hecho en la creación del IPGH.

La valía intelectual de los concurrentes y de las instituciones que representaban contribuyó a que la instalación de la Comisión de Historia tuviera tan alta significación para la historiografía mexicana. Estuvieron ahí, desde Jaime Torres Bodet, Secretario de Relaciones Exteriores en representación del presidente Miguel Alemán, pasando por funcionarios y directores de instituciones como Manuel Gual y Vidal, Alfonso Caso, Ignacio Marquina, Alfonso Reyes, Samuel Ramos, Atanasio G. Saravia, Vito Alessio Robles, entre otros. En los comités de recepción, información, publicidad, etcétera, tomaron parte Antonio Pompa y Pompa, Salvador Toscano, Agustín Yáñez, Juan Comas, entre otros. Como observadores de países no miembros del IPGH o representantes de organismos internacionales estuvieron: Rafael Altamira, Pedro Bosch Gimpera, José María Miquel i Vergés, François Chevalier, Alfred Mètraux, Manuel Martínez Baez y Manuel Gamio, entre los más importantes. De instituciones científicas no mexicanas: el historiador cubano Emeterio Santovenia, los historiadores estadounidenses Lewis Hanke, Arthur P. Witaker y Frank Tannenbaum, y el filósofo hispano-guatemalteco Luis Recasens Siches. De instituciones mexicanas: don José Ignacio Dávila Garibi, Edmundo O’Gorman, Julio Jiménez Rueda, Agustín Millares Carlo, José Miranda, Manuel Toussaint, Eusebio Dávalos Hurtado, Agustín Cué 
Cánovas, Arturo Arnaiz y Freg, Pablo Martínez del Río, Rafael García Granados, etcétera. Por último, cabe decir que estuvieron los miembros nacionales de Argentina, Bolivia, Colombia, Brasil, Costa Rica, Cuba, Chile, Ecuador, Estados Unidos, El Salvador, Guatemala, Haití, Honduras, Nicaragua, Panamá, Perú, República Dominicana, Uruguay y Venezuela. ${ }^{25}$

Como es de suponer, las resoluciones relativas a historia se habían acumulado desde la creación del IPGH, y las sugerencias que nacieron con motivo de la instalación de la Comisión, Silvio Zavala sólo pudo calificarlas como excesivas en su informe del 20 de octubre de 1947. Éstas incluían la conservación y estudio de restos arqueológicos y monumentos históricos, el fomento a la organización de museos y archivos históricos de América, la divulgación de documentos de historia americana conservados en otras partes del mundo, el patrocinio de investigaciones y publicaciones, promoción del acercamiento entre personas e instituciones que cultivan disciplinas afines a la historia, preparar una historia de América, cooperar en los programas y textos de historia del continente, formar una guía lo más completa posible de personas e instituciones que cultivan la historia de América, etcétera. De todas ellas, Silvio Zavala advirtió la necesidad de una selección de acuerdo a las posibilidades humanas y económicas para un programa hacedero de alcances verdaderamente interamericanos, y para tal selección, por supuesto que se tomaría en cuenta a los delegados de los gobiernos, pero la voz más amplia se concedería a la opinión científica del continente.

Para $1952^{26}$, Zavala podía ya dar cuenta de los encargos de más inmediata y práctica realización que se habían llevado a cabo, y que comprendían aspectos instrumentales, informativos, y de creación historiográfica tales como la elaboración de guías, la formación de una biblioteca de historiografía americana, la colaboración en la enseñanza de la historia y la difusión de sus técnicas, informes sobre misiones y conservación de monumentos, publicaciones periódicas con amplia información bibliográfica, etcétera. Esto sin contar que en 1950 se había aprobado el Programa de Historia de América con la ayuda económica del Comité del Centenario de José Martí y la Fundación Rockefeller.

25 Primera Reunión de Consulta de la Comisión de Historia del Instituto Panamericano de Geografía e Historia, México, IPGH. Comisión de Historia, 1947, pp. 71-72. Resulta interesante ver aquí el nombre de las instituciones a las que todos los intelectuales mencionados representaban, así como los nombres de quienes, sólo por razones de espacio no hemos mencionado, pero que estuvieron presentes y hoy son todavía más importantes que entonces.

26 Silvio Zavala, El Instituto Panamericano de Geografia e Historia, México, IPGH. Comisión de Historia, 1952, p. 19. 


\section{El Programa de Historia de América y la Reunión de MonTERREY}

Aunque el IPGH contaba entre sus resoluciones relativas a historia y ciencias afines tomadas desde $1922^{27}$, fue hasta octubre de 1950 cuando la $\mathrm{V}$ asamblea del Instituto reunida en Santiago de Chile otorgó la aprobación inicial para el Programa de Historia de América, proyecto que combinaría aquella añeja preocupación del Instituto, con la no menos persistente de cooperar para la revisión de los programas y textos de historia de América, con el fin de fomentar, dentro del respeto a la verdad histórica y la amistad, el conocimiento mutuo y la colaboración entre los pueblos del continente.

Así, a partir de 1953, con la reunión de colaboradores del Programa en La Habana y la ayuda del Comité del Centenario de José Martí, se publicaron en México la mayor parte de las contribuciones preparadas. El Programa estaba dividido en tres periodos: indígena, colonial y nacional, cuyos coordinadores fueron Pedro Armillas, Silvio Zavala y Charles C. Griffin, respectivamente. Para tal periodo Silvio Zavala escribió Hispanoamérica Septentrional y Media (1953), cuya información contenida no era lo más importante, sino el enfoque, la estructuración de los amplísimos temas a abordar, y las ideas generales y observaciones metodológicas que servirían incluso para todo el proyecto, del que además Silvio Zavala era director general. ${ }^{28}$

Sin embargo, el resultado final de la colaboración para el periodo colonial, y que Silvio Zavala debía elaborar integrando las diversas contribuciones regionales, excedió con mucho los límites que el IPGH se había fijado para el Programa. Por esta razón, el Instituto sólo publicó un resumen elaborado por Max Savelle y que Antonio Alatorre tradujo con el título de Programa de historia de América en la época colonial. La obra que efectivamente recogió con un carácter general las conclusiones de las múltiples monografías del programa fue El mundo americano en la época colonial (Porrúa, 1967, 2 v.), una obra de Silvio Zavala con la colaboración de María del Carmen Velázquez.

Perteneciente a estos años vale la pena mencionar también el que Lewis Hanke recordó como el proyecto más significativo que emprendió con Silvio Zavala: la organización del Primer Congreso de Historiadores Mexicanos y Estadounidenses, que se celebró en Monterrey en septiembre de 1949 con el

27 Vid., Resoluciones relativas a la Historia y a las ciencias afines tomadas por las diversas Asambleas del Instituto Panamericano de Geografia e Historia (1929-1946), México, IPGH, Comisión de Historia, 1947, pp.10 y 18.

28 Un testimonio privilegiado de quien personalmente se benefició de estas primeras publicaciones en sus años escolares es el de Álvaro Matute, "Silvio Zavala. Decano de los historiadores", Revista de la Universidad de México, Ciudad de México, núm. 133, 2015, pp. 34-37. 
patrocinio de la Academia de Ciencias Históricas de Monterrey, la American Historical Asociation y el Instituto Nacional de Antropología e Historia (INAH). ${ }^{29}$

La idea de la reunión había sido pensada desde un año antes por lo dramático que sería celebrarla un siglo después de la guerra entre los dos países, pero los ánimos estaban todavía encendidos, y aunque prudentemente se decidió esperar un poco, el mes elegido hizo que algunos mexicanos como Alfonso Reyes aconsejaran no permanecer en la ciudad de México, por el período de Guerra Fría que se vivía, y porque los izquierdistas — se supone que con alguna ayuda del exterior - habían organizado uno de aquellos congresos de paz que se multiplicaban por todas partes.

De acuerdo con Hanke, Zavala insistió en un planteamiento amplio para el congreso, la inclusión de sesiones sobre enseñanza de la historia y de acontecimientos y movimientos históricos específicos, la participación de estudiosos norteamericanos no sólo de historia mexicana, y la inclusión de académicos latinoamericanos (el historiador peruano Jorge Basadre y el ensayista venezolano Mariano Picón Salas). En los escritos donde Zavala dio cuenta del hecho ${ }^{30}$, destacó sobre todo la importancia que tenía reunir a dos países tan distintos y con una noción no siempre clara de la historia de la nación contigua, que además se habían ya encontrado en oposición en colaboración, antes en diversos renglones de la vida, pero nunca en un intercambio de su pensamiento histórico que tanto tocaba a la conciencia nacional de cada pueblo. Y tampoco dejaba de lado las cuestiones inmediatas, tales como las características del intelectual norteamericano, más cuidadoso de la información, ante el hispanoamericano generalmente más cuidadoso de las problemáticas; la apariencia desmesurada del diálogo en tamaño, fuerza y riqueza, que el hispanoamericano compensaba con su mayor raigambre histórica; e incluso, llega a lamentar la ausencia del elemento de cultura negro por ambos lados en el evento. La celebración fue, en resumen, cortés, aunque en las resoluciones finales daba la impresión de que México no había conseguido sino la "certificación" de que, efectivamente, estaba realizando trabajos útiles para la investigación histórica seria.

Para la historiografía mexicana también fue importante la celebración de la Primera Conferencia de Mesa Redonda para el Estudio de la Técnica de la Enseñanza de la Historia, del que se desprendió un Seminario para el Estudio de la Técnica de la Enseñanza de la Historia que se reunió en marzo de 1945 y que, entre otras cosas, sirvió para que en 1948 el IPGH publicara un volumen

29 Lewis Hanke, "Experiencias con Silvio Zavala, 1933-1949: algunos recuerdos al azar", Historia Mexicana, XXXVIII-4, abril-junio, 1989, pp.601-607.

30 Vid. "En torno al Primer Congreso de Historiadores de México y los Estados Unidos", Revista de Historia de América, 28, diciembre 1949, pp. 436-440 y también lo escrito en el Primer Congreso de Historiadores de México y los Estados Unidos, México, 1949. 
colectivo sobre la enseñanza de la historia en México, pero también desembocó en las memorables tres sesiones que en junio de 1945 se dedicaron a debatir sobre el problema de la verdad histórica, con una fallida polémica entre Silvio Zavala y Edmundo O'Gorman, pero que sin duda animó reflexiones de muy largo alcance. ${ }^{31}$ Fue fallida porque Silvio Zavala no estuvo presente el día de la reunión, pero quienes presentaron sus ponencias y quienes tomaron la palabra, dejaron testimonio de posiciones y de un formato en su defensa como el que tal vez no se ha vuelto a ver durante mucho tiempo.

\section{LA CONSOLIDACIÓN DE UN PROYECTO INTELECTUAL}

Los primeros años de la década de los cincuenta fueron menos afortunados para Silvio Zavala en su vida institucional. El cargo de director en el Museo Nacional de Historia todavía le deparaba una intervención importante en la historia de la historiografía mexicana. En septiembre de 1949 Eulalia Guzmán, investigadora del INAH, hizo público lo que pareció ser el descubrimiento de los restos de Cuauhtémoc en el pueblo de Ichcateopan, Guerrero. Los primeros peritajes aseguraron que los restos eran auténticos y dieron pie para que la prensa y algunos funcionarios se apresuraran en las consecuencias del hecho sobre la identidad nacional, aprovechando el clima propicio en que se encontraba el país, en busca de la mexicanidad. ${ }^{32}$

Sin embargo, la Secretaría de Educación Pública se dio tiempo para nombrar una comisión de expertos que se encargara de dictaminar sobre el hallazgo. Entre otras personalidades, se eligió a Ignacio Marquina, Eusebio Dávalos Hurtado y Silvio Zavala. Este último encargado del análisis de los supuestos documentos del siglo XVI en los que, se aseguraba, podía leerse cómo Motolinía había depositado los restos de Cuauhtémoc en la iglesia del lugar, e incluso firmaba el documento. Zavala fue también quien redactó el resumen final del dictamen, donde no sólo probó la inautenticidad de los documentos de los restos, sino también la postura de quienes sostenían que a la figura de Cuauhtémoc y al pueblo de México convenía que se ocultara piadosamente la verdad, pues era mejor envolver casos como éste en la atmósfera nebulosa del mito. Tomando en cuenta el temperamento sereno de Silvio Zavala, aquel dictamen final fue una contundente y casi violenta defensa del conocimiento científico contra afirmaciones antihistóricas

31 Las conferencias y la importancia que alcanzó la discusión pueden verse en Álvaro Matute, La teoría de la historia en México (1940-1968), México, Fondo de Cultura Económica, 2015, 358 pp., por su parte, Guillermo Zermeño analizó parte de tales reflexiones en su libro de La cultura moderna de la historia. Una aproximación teórica e historiográfica, México, El Colegio de México, 2002.

32 Cfr. Alejandra Moreno Toscano, Los hallazgos de Ichcateopan: 1949-1951, México, UNAM. Instituto de Investigaciones Históricas, 1980 (Dictámenes Ichcateopan; 4). 
de cualquier tipo, arguyendo que los verdaderos héroes no se sostenían sobre pedestales falsos, que afortunadamente el pueblo mexicano había ya superado la etapa infantil del pupilaje y no había por qué suponerle impreparado para enfrentarse a la verdad, cuyo ocultamiento llevaba de por medio el prestigio de la ciencia en México y el riesgo de inmortalizar la ligereza de autoridades, sabios y educadores mexicanos al mediar el siglo $\mathrm{Xx}^{33}$

El resultado de todo esto fueron los ataques de la prensa a los miembros de la comisión y a la Sociedad Mexicana de Antropología; el nombramiento de otra comisión que no decidió nada con seguridad; y para Silvio Zavala parece ser que hasta llegó a provocar un mal entendido con el presidente Miguel Alemán y con el entonces candidato Adolfo Ruiz Cortines, debido a las "conspiraciones" del subsecretario de educación pública a quien Manuel Sandoval Vallarta debió sustituir. De cualquier forma, en carta del 10 de febrero de 1954 enviada al propio Zavala, Alfonso Reyes pintó su situación laboral en México con muy pocas opciones.

En ese año, Silvio Zavala pasó de Harvard a París, donde se instaló con muchos problemas económicos en los que Reyes, Cosío Villegas y Marquina trataron de ayudarlo, pues además de esto, Zavala tenía dificultades legales en México para conservar a su hija contra las pretensiones de su madre, a quien asesoraba el licenciado Brito Foucher. Para mediados de 1954 Silvio Zavala se encontraba prácticamente refugiado en una aldea de Francia, y fue dos años después cuando consiguió asegurar su situación en París como consejero cultural de la embajada de México, delegado permanente de México ante la UNESCO y presidente y colaborador de la revista Nouvelles du Mexique fundada por Jaime Torres Bodet.

Cuando Zavala regresó a México en 1963 para asumir la presidencia de El Colegio de México, desconocía de cerca los vaivenes experimentados por la institución, los del país, y los de la vida académica mexicana. Además, su estilo personal, diferente al de Daniel Cosío Villegas, que lo había antecedido en el cargo, no sólo cambió la vida cotidiana de El Colegio, sino también su esfera de acción. La apertura y la cooperación con las universidades de provincia fueron sustituidas por una vuelta sobre sí mismos y hacia el extranjero. Las transformaciones administrativas y formales incluyeron la captación como académicos a sus propios egresados, la fundación de un departamento de publicaciones, el enriquecimiento del programa del Centro de Estudios Históricos (CEH), la reincorporación de Gaos, Miranda y Muedra, la incorporación al CEH de los ahora connotados

33 El hallazgo de Ichcateopan. Dictamen que rinde la Comisión designada por acuerdo del C. Secretario de Educación Pública, en relación con las investigaciones y exploraciones realizadas en Ichcateopan, Guerrero. Sobretiro del t. 11 de la Revista Mexicana de Estudios Antropológicos, México, 1950, pp. 294-295. 
Leopoldo Zea y Luis Villoro, la meticulosa evaluación de los alumnos y del programa del $\mathrm{CEH}$, etcétera. Así mismo, Silvio Zavala impulsó al Centro para colaborar en la organización de eventos internacionales, mientras el Seminario de historia contemporánea de México abandonó el proyecto de Cosío Villegas por historiar la Revolución mexicana en todas sus dimensiones, y se redujo a cumplir con encargos oficiales de las Cámaras de Senadores y de Diputados, y de la Secretaría de Hacienda. En el aspecto económico, Silvio Zavala coadyuvó a la estabilidad de El Colegio con la recepción de otros subsidios, además de los de la Fundación Rockefeller; de la Fundación Ford y de la UNESCO, lo que permitió que para el vigesimoquinto aniversario de El Colegio (1965), Silvio Zavala aprovechara para inaugurar el nuevo y bien acondicionado edificio para El Colegio antes de abandonar su cargo, con la llegada de Gustavo Díaz Ordaz a la presencia de la República.

\section{Conclusiones}

Parece claro que Silvio Zavala estuvo muy lejos de ser siquiera el simple neopositivista que algunos de sus contemporáneos, e incluso algunos de sus alumnos creyeron identificar. La admiración por la obra de Francisco del Paso y Troncoso estuvo en sus inicios, colaboró de cerca con don Genaro Estrada y parece haber sido el gran heredero de Rafael Altamira y Crevea, pero para hablar de Silvio Zavala no deben olvidarse tampoco a todos aquellos a quienes él mismo destacó, no tanto por su cientificismo o su método, sino por su afán histórico comparativo, y por considerarlos más bien historiadores de la civilización. De ahí que en el ámbito de la historiografía mundial, Silvio Zavala se encontrara comprensiblemente más atento a los trabajos escritos en Estados Unidos y Francia, recibiendo la generosidad de Paul Rivet y disfrutando de la hospitalidad de Lucien Febvre o Fernand Braudel, pero con una visión crítica que siempre lo llevó a equiparar, frente a las contribuciones de aquéllos, la meritoria labor de muchos hispanoamericanos.

Es cierto que Silvio Zavala se enorgullecía de contar en México con una colección completa de la revista Annales, en una época en que muy pocos podían conocerla de primera mano. Gracias a sus colaboraciones con Paul Rivet, Jean Sarrailh y Marcel Bataillon dijo haberse sentido en Francia como en casa, pero desde el principio, la idea de crear en México un centro para la formación de investigadores, no sólo tuvo en mente apoyar a becarios mexicanos, sino también abrir espacios a todos los hispanoamericanos, como lo fueron el cubano Julio Le Riverend, la puertorriqueña Isabel Gutiérrez del Arroyo, el venezolano Eduardo Arcila Farías y el peruano Luis Muro, entre otros. A todos ellos, Silvio Zavala los reconoció como sus discípulos.

Y de la misma manera que habría de escribir acerca del americanismo de Rafael Altamira, o recordar sentidamente a Ramón Iglesia y Marcel Bataillon, 
en 1981, Silvio Zavala escribió acerca de Gilberto Freyre como un amigo e hispanista bajo cuya guía también podríamos ensanchar nuestros horizontes y "recoger los beneficios de la actuación en compañía de pueblos afines, unidos por vínculos más estrechos de comprensión, fraternidad y solidaridad humana, a pesar de las distancias físicas y espirituales subsistentes". ${ }^{34}$

Es esto lo que me parece que genera la revisión de la vida intelectual de Silvio Zavala, y si algún beneficio pueden reportar trabajos como éste, ello radica en la posibilidad de ampliar nuestro campo de visión hacia lo que es la historia de la historiografía, hacia lo fecunda que puede ser la historia intelectual y hacia las múltiples variantes que nos remiten conceptos como los de "red intelectual" y "sociedades de pensamiento", que si bien no son equivalentes, sí pueden ser complementarias en la comprensión histórica. Si se considera el discurrir de una vida como algo variado y complejo, la de Silvio Zavala se nos presenta siempre en el borde del espacio geográfico, político, simbólico y espiritual americano al que siempre quiso extender la historia. Sí el mundo americano, pero desde el punto de vista de la historia de la humanidad.

\section{BibLIOGRAFÍA}

Agulhon, Maurice, El círculo burgués. La sociabilidad en Francia, 1810-1848, seguido de Una pequeña autobiografía intelectual, Margarita Polo (trad.), edición de Pilar González Bernaldo, Buenos Aires, Siglo Veintiuno, 2009.

Alfonso Reyes y los estudios latinoamericanos, edición de Adela Pineda Franco e Ignacio M. Sánchez Prado, Pittsburgh, Universidad de Pittsburgh. Instituto Internacional de Literatura Iberoamericana, 2004.

Alfonso Reyes y los intelectuales colombianos. Diálogo epistolar, recopilación, introducción y aclaraciones Adolfo Caicedo Palacios, Bogotá, Universidad de Los Andes, 2009.

Altamirano, Carlos, Historia de los intelectuales en América Latina. II. Los avatares de la "ciudad letrada" en el siglo XX, Buenos Aires, Katz, 2010.

América en el pensamiento de Alfonso Reyes, José Luis Martínez (pról. y selecc.), Fondo de Cultura Económica, México, 2012.

Biobibliografía de Silvio Zavala, 2a. ed. México, El Colegio Nacional, 1993, p. 29 y 45.

Certeau, Michel de, La escritura de la historia, de Jorge López Moctezuma (trad.), México, Universidad Iberoamericana, 1985.

Edición anotada de las entrevistas de Rafael Heliodoro Valle en la revista Universidad. Mensual de Cultura Popular 1936-1938, coordinación general, edición y estudio preliminar, Raquel Mosqueda Rivera, equipo editorial, María de Lourdes Ángeles Trujillo, Víctor Alejandro Bravo Morales, Dafne Iliana Guerra

34 Silvio Zavala, Aportaciones históricas, prólogo de Alejandra Moreno Toscano, México, Centro de Estudios Económicos y Sociales del Tercer Mundo, A.C./Nueva Imagen, 1985, p. 303. 
Alvarado, Lucero Alejandra Rivera Cano, México, Instituto de Investigaciones Filológicas, UNAM, 2015.

Ellison, Fred P., Alfonso Reyes y el Brasil. Un mexicano entre los cariocas, México, Consejo Nacional para la Cultura y las Artes, 2000.

Fernández Castro, Roberto, "Liberalismo y civilización en la historia de la colonización española", Escribir la historia en el siglo XX. Treinta lecturas, Evelia Trejo y Álvaro Matute, (editores), México, Instituto de Investigaciones Históricas, UNAM, 2009, pp. 127-144.

Fernández Castro, Roberto, “Edmundo O'Gorman y la fundamentación fenomenológica de la ciencia de la historia en Crisis y porvenir", Historia y Grafia, México, Universidad Iberoamericana, núm. 47, julio-diciembre, 2016, pp. 217-250.

Fernández Castro, Roberto, "Silvio Zavala. Tributo a un historiador centenario", Memorias de la Academia Mexicana de la Historia, México, tomo L, 2009, pp. 7-32.

Fronteras conquistadas. Correspondencia Alfonso Reyes/Silvio Zavala, 1937-1958, compilación, introducción y notas de Alberto Enríquez Perea, México, El Colegio de México, 1998.

Gadamer, Hans-Georg, Verdad y método, Ana Agud Aparicio y Rafael de Agapito (trad.), Salamanca, Ediciones Sígueme, 1992, 704 pp. (Hermeneia, 7).

Granados, "La corriente cultural de la JAE en México: El Instituto Hispano-Mexicano de Intercambio Universitario, 1925-1930", Revista de Indias, España, vol. LXVII, núm. 239, enero-abril, 2007, pp. 103-124.

Guerra, François-Xavier, México. Del Antiguo Régimen a la revolución, 2a . edición, Sergio Fernández Bravo (trad.), México, Fondo de Cultura Económica, 1991.

El hallazgo de Ichcateopan. Dictamen que rinde la Comisión designada por acuerdo del C. Secretario de Educación Pública, en relación con las investigaciones y exploraciones realizadas en Ichcateopan, Guerrero. Sobretiro del t. 11 de la Revista Mexicana de Estudios Antropológicos, México, 1950.

Hanke, Lewis, "En torno al Primer Congreso de Historiadores de México y los Estados Unidos", Revista de Historia de América, núm. 28, diciembre, 1949, pp. 436440.

Hanke, Lewis, "Experiencias con Silvio Zavala, 1933-1949: algunos recuerdos al azar", Historia Mexicana, XXXVIII-4, abril-junio, 1989, pp. 601-607.

Lida, Clara E. y José Antonio Matesanz, El Colegio de México: una hazaña cultural 1940-1962, México, El Colegio de México, 1990.

Lida, Clara E., La casa de España en México, con la colaboración de José Antonio Matesanz, México, El Colegio de México, 1988.

Matute, Álvaro, "Silvio Zavala. Decano de los historiadores", Revista de la Universidad de México, Ciudad de México, núm. 133, 2015.

Matute, Álvaro, La teoría de la historia en México (1940-1968), México, Fondo de Cultura Económica, 2015.

Memoria del primer Congreso de historiadores de México y los Estados Unidos celebrado en la Ciudad de Monterrey Nuevo León, México, del 4 al 9 de septiembre de 1949, México, Cultura, 1949.

México en Sur, antología, edición e introducción de Gerardo Villadelángel Viñas, México, Fondo de Cultura Económica, 2014. 
Meyer, Jean, coord., Egohistorias: El amor a Clio, México, Centre d'Etudes Mexicaines et Centramèricaines, 1993.

Moreno Toscano, Alejandra, Los hallazgos de Ichcateopan: 1949-1951, México, UNAM. Instituto de Investigaciones Históricas, 1980.

Pelosi, Hebe Carmen, "Las redes sociales de Rafael Altamira historiador", Canelobre, núm. 59, 2012, pp. 46-54.

Pita González, Alexandra, Redes intelectuales transnacionales en América Latina durante la entreguerra, México, Universidad de Colima/Miguel Ángel Porrúa, 2016.

Prado, Gustavo H., Las lecciones historiográficas de Rafael Altamira en Argentina (1909). Apuntes sobre ciencia, universidad y pedagogía patriótica, Oviedo, Universidad de Oviedo, 2010, 298 pp.

Primera Reunión de Consulta de la Comisión de Historia del Instituto Panamericano de Geografia e Historia, México, IPGH, Comisión de Historia, 1947.

Resoluciones relativas a la Historia y a las ciencias afines tomadas por las diversas Asambleas del Instituto Panamericano de Geografía e Historia (1929-1946), México, IPGH. Comisión de Historia, 1947.

Reyes, Alfonso, Vocación de América. Antología, prólogo y selección de Víctor Díaz Arciniega, México, Fondo de Cultura Económica, 1989.

20 epistolarios rioplatenses de Alfonso Reyes, compilador Serge I. Zaïtzeff, México, El Colegio Nacional, 2008, 425 pp.

Vélez, Palmira, La historiografía americanista en España 1955-1936, Madrid/ Iberoamericana; Frankfurt an Main/Vervuert, 2007.

Wilkinson, James D., La resistencia intelectual en Europa, traducción de Juan José Utrilla, México, Fondo de Cultura Económica, 1989.

Zavala, Silvio, Aportaciones históricas, prólogo de Alejandra Moreno Toscano, México, Centro de Estudios Económicos y Sociales del Tercer Mundo, A.C./ Nueva Imagen, 1985.

Zavala, Silvio, El Instituto Panamericano de Geografia e Historia, México, IPGH. Comisión de Historia, 1952.

, "Orígenes del Centro de Estudios Históricos de El Colegio de México" en Cincuenta años de historia en México, (coords.) Alicia Hernández Chávez y José Miño Grijalva, México, El Colegio de México, 2 v.

, Primeras jornadas, 1931-1937, edición e introducción Andrés Lira, recopilación y notas Alberto Enríquez Perea, México, El Colegio de México, 2009. 